\title{
NAVEGANDO ENTRE A ETNOECOLOGIA E A EDUCAÇÃO AMBIENTAL: NARRATIVAS DE ESTUDANTES DE UMA ESCOLA DE GOVERNADOR CELSO RAMOS (SC)
}

Daniel Ganzarolli Martins ${ }^{1}$

Natalia Hanazaki ${ }^{2}$

Aline Gevaerd Krelling ${ }^{3}$

Resumo: Esta pesquisa tem como objetivo discutir a contribuição dos saberes etnoecológicos de um grupo de estudantes em Governador Celso Ramos (SC) na aplicação de atividades dialógicas em Educação Ambiental. Em 2014 foram realizadas oficinas educativas que exploraram temas relacionados à sociobiodiversidade da Área de Proteção Ambiental do Anhatomirim com estudantes do $7^{\circ}$ e $8^{\circ}$ ano de uma escola municipal. São discutidas as percepções narradas pelos alunos acerca dos seres vivos neste espaço, as mudanças ambientais ocorridas e a realização de uma entrevista com uma antiga moradora local. Esta pesquisa apresenta as potencialidades existentes nas trocas de saberes etnoecológicos comunitários e uma educação ambiental dialógica.

Palavras-chave: Percepções Ambientais; Narrativas; Etnobiologia; Educação Ambiental Dialógica.

\footnotetext{
1 Licenciado e Bacharel em Ciências Biológicas pela Universidade Federal de Santa Catarina. E-mail: danielgmk9@gmail.com

2 Professora do Departamento de Ecologia e Zoologia da Universidade Federal de Santa Catarina. E-mail: natalia.hanazaki@ufsc.br

3 Professora do Instituto Federal de Santa Catarina - Câmpus Jaraguá do Sul. E-mail: aline.krelling@gmail.com
} 


\section{Introdução}

Os conhecimentos empíricos associados aos ambientes ditos naturais fazem parte do campo de pesquisa da Etnoecologia, sendo que essa área apresenta uma ampla diversidade conceitual (ALVES; SOUTO, 2010). O presente trabalho utiliza-se da definição de Marques (1995), que posicionou a Etnoecologia como o estudo das interações entre a humanidade e o restante da ecosfera, através da busca da compreensão dos sentimentos, comportamentos, conhecimentos e crenças a respeito da natureza, característicos de uma espécie biológica (Homo sapiens) altamente polimórfica, fenotipicamente plástica e ontogeneticamente dinâmica. De acordo com Marques (1995), a Etnoecologia tem como objetivo principal a integração entre o conhecimento ecológico tradicional e o conhecimento ecológico científico, tendo sua ênfase na diversidade biocultural.

Atualmente, diferentes pesquisas etnoecológicas estão sendo desenvolvidas mostrando como os saberes tradicionais podem ser utilizados para apoiar projetos educacionais. Um estudo realizado por Almeida (2014) em escolas no Macapá demonstrou como determinados animais são perseguidos por estudantes por serem associados culturalmente ao mal e às doenças, como é o caso de morcegos e insetos. O reconhecimento dessas percepções prévias pelos professores possibilitou reconstruções e reflexões na forma de abordar o ensino de zoologia. Em províncias do noroeste argentino, Vilá (2014) buscou explorar as relações entre camelídeos nativos como a lhama, a alpaca e a vicunha, com os povos andinos. Trabalhando em colaboração com professores e estudantes de escolas dessa região, Vilá (2014) mostrou a riqueza de significações culturais que existem para com esses animais, incluindo maneiras de abordar essa riqueza no ambiente escolar. A autora sugere a elaboração de uma educação ambiental etnobiológica, que inclua também saberes locais e seus valores associados.

Hanazaki e Freitas (2011) argumentam que pesquisas em Etnoecologia deveriam subsidiar programas educacionais nas comunidades estudadas, tendo em vista a valorização da cultura e de perspectivas locais. A conexão entre a Etnoecologia, os estudos sobre percepções e a educação já rendeu investigações tal como a apresentada por Gandolfo et al. (2010), que descrevem um trabalho de educação ambiental junto a crianças usando de conhecimentos e folclore associados a insetos presentes em uma comunidade na ilha de Santa Catarina.

Quando presentes, ações educativas no escopo da Educação Ambiental com comunidades de entorno de Unidades de Conservação da Natureza frequentemente desenvolvem ações com viés autoritário e prioritariamente fiscalizador (ARRUDA, 1999). Gomes e Silva (2002) também alertam para o perigo do educador privilegiar a homogeneização dos currículos, dos saberes, dos métodos, da avaliação e da organização da escola, tendo-se em consideração que a sociedade brasileira é pluriétnica e pluricultural. NorbergHodge (2009) coloca que o sistema padronizado da educação escolar moderna 
foi, e continua sendo, um dos grandes atores do acelerado processo de perda cultural e ambiental mundial. Entretanto, essa autora também considera que a educação está sendo um elemento chave na reversão destes mesmos processos, atuando através da formação de elos e saberes que podem fortalecer comunidades locais.

Afinal, podemos questionar: como o meio acadêmico deve dialogar com esses outros universos e culturas, sem estar reforçando uma pretensiosa desigualdade entre os pesquisadores-educadores $e$ as pessoas que construíram a maior parte do seu saber fora do ensino formal? A Etnoecologia converge com Paulo Freire ao refletirmos de que não há saber mais ou saber menos, mas sim saberes diferentes (FREIRE, 2011). Freire (2011) apresenta o caráter dialógico do seu ideal educativo ao colocar que o professor e 0 estudante são ambos educadores e educandos, em que ninguém é o único detentor de conhecimento e todos são capazes tanto de aprender quanto de ensinar. Isto é bem colocado em sua ressonante frase "ninguém educa ninguém, ninguém se educa a si mesmo, os homens se educam entre si, mediatizados pelo mundo" (FREIRE, 2011, p.95).

Dessa forma, práticas educativas com orientação dialógica podem vir a ser aprimoradas através de estudos que valorizem saberes etnoecológicos, próprios de muitas comunidades. Dada a importância de potencializar a articulação entre a Etnoecologia e o ensino, o objetivo desse artigo é discutir a contribuição dos saberes etnoecológicos de uma comunidade próxima a uma Unidade de Conservação (UC) na aplicação de atividades dialógicas em Educação Ambiental.

\section{Local de estudo}

A Área de Proteção Ambiental do Anhatomirim (APAA) localiza-se na sua porção sul e menos urbanizada do município de Governador Celso Ramos, além de estar cerca de $41 \mathrm{~km}$ ao norte de Florianópolis. Esta UC foi criada em 1992 e se enquadra entre as UC de Uso Sustentável, as quais permitem a permanência de comunidades humanas em seu interior e a exploração sustentável dos seus recursos (BRASIL, 2000). A criação da APAA teve como objetivos principais a conservação dos remanescentes de Floresta Ombrófila Densa da Mata Atlântica na região e a proteção das áreas de alimentação, reprodução e descanso da população de boto-cinza (Sotalia guianensis) (ICMBIO, 2013a). Apesar de mais de duas décadas após sua criação, ainda há um marcante desconhecimento da população inserida na APAA sobre o seu processo de manejo e os seus limites territoriais (ALVES; HANAZAKI, 2015). 


\section{Metodologia}

\section{Planejamento pedagógico}

As oficinas de educação ambiental foram feitas junto à Escola de Educação Básica Municipal Maria Amália Cardoso, situada no bairro da Fazenda da Armação, em Governador Celso Ramos (SC). Esta escola atende ao bairro mais populoso que faz parte da APAA (ICMBIO, 2013b). A escola localiza-se no entorno próximo da APAA e muitos dos seus estudantes vivem em áreas no interior da UC. Tal como planejado com a direção da escola em contatos prévios ${ }^{4}$, as atividades foram desenvolvidas no período de contraturno no formato de oficinas extraclasse. Isso se deu para que as oficinas não substituíssem o tempo das aulas dos professores, de acordo com a direção da escola, possibilitando também uma maior liberdade de atuação do projeto.

A participação no projeto foi de caráter opcional para os estudantes, contando com seu interesse pessoal em desenvolver as dinâmicas de educação ambiental no contraturno escolar. Dessa forma, foi realizado o projeto de educação ambiental intitulado "Descobrindo Anhatomirim", que foi divulgado para as turmas de estudantes em parceria com a direção do colégio. Aos alunos e alunas que estivessem interessados em participar, foi solicitado que preenchessem um questionário que visava registrar algumas informações básicas sobre os jovens e suas visões iniciais sobre a APAA, além de colher sugestões e opiniões para o direcionamento das oficinas.

Conjuntamente ao questionário, também foi entregue aos responsáveis pelos alunos envolvidos um termo de consentimento livre esclarecido que explicava acerca do projeto, seus objetivos e como se daria o uso do material de pesquisa. $O$ presente trabalho está incluído no projeto 35007214.4.0000.0118 (Comitê de Ética em Pesquisas com Seres Humanos da UFSC), tendo também a autorização da direção da escola, da secretaria de educação do município de Governador Celso Ramos e dos adultos responsáveis pelos estudantes. Um termo de assentimento também foi apresentado e assinado pelos estudantes, pois todos eram menores de 18 anos.

A pesquisa teve como público alvo os estudantes dos anos finais do ensino fundamental. Porém, dado o baixo interesse da turma de 9o ano da escola em se envolver com as oficinas, estas foram feitas com os alunos interessados de uma turma de $7^{\circ}$ ano e de duas turmas de $8^{\circ s}$ anos da escola. As oficinas ocorreram no período de 11/09 a 30/10 de 2014, totalizando oito encontros intercalados em oito semanas consecutivas. As atividades possuíram uma duração média de uma hora e trinta minutos, com exceção de duas saídas de campo que duraram aproximadamente 4 horas. As oficinas tiveram a presença variável de 6 a 16 alunos participantes.

${ }^{4}$ Encontros realizados nos dias 09/04/2014 e 11/06/2014. 
Foram propostos alguns eixos temáticos que guiaram as atividades desenvolvidas nas oficinas. Estes temas iniciais de relevância social, ambiental e cultural tiveram como base tópicos levantados no plano de manejo da APAA (ICMBIO, 2013c) e nas pesquisas de Coutinho et al. (2010) e Alves e Hanazaki (2015) na região, além do acompanhamento das reuniões do plano gestor da APAA que ocorreram no primeiro semestre de 2014. As questões levantadas a partir destes trabalhos envolviam uma diversidade de temas que foram discutidos ao longo das oficinas, como, por exemplo, a pesca artesanal na região, as problemáticas socioambientais que estavam presentes e as percepções das pessoas para com a unidade de conservação. Entretanto, os temas das oficinas foram também reorganizados coletivamente a partir do constante diálogo com os estudantes, já que logo no primeiro encontro foi apresentado o plano de atividades com um calendário aos alunos, o qual foi adaptado a partir dessa interação. Atividades propostas pelos alunos nessa dinâmica inicial incluíram a realização de mais saídas de campo e o uso de dinâmicas e jogos teatrais, ambas incorporadas no decorrer das oficinas.

Os oito encontros com os alunos e as alunas foram conduzidos pelo primeiro autor do trabalho e versaram sobre os seguintes tópicos: 1) Diálogo inicial sobre o Projeto e apresentação do cronograma; $2^{\circ}$ ) Discussão sobre as transformações no espaço da APAA através do uso de fotografias antigas de Governador Celso Ramos; 3ํ) Saída de campo para a cachoeira da Armação, onde os estudantes aprenderam sobre a biodiversidade e a hidrografia do entorno da escola; 4ㅇ) Teatralizando reflexões sobre a APAA, no qual foi realizada uma dinâmica em que os estudantes tiveram de interpretar diferentes personagens diante de um conflito socioambiental; $5^{\circ}$ ) Plantas medicinais e conhecimento tradicional, atividade que envolveu também um plantio na horta escolar; 6ㅇ) Discussão através da apresentação de audiovisuais com temas socioambientais; $7^{\circ}$ ) Saída de campo para a llha de Anhatomirim, região da APAA, onde puderam ser discutidas a importância histórica, cultural e ambiental da unidade de conservação; $8^{\circ}$ ) Entrevista com Aléci Monteiro, uma antiga moradora com vasto conhecimento sobre causos e lendas da região, juntamente com a finalização do projeto. Essa quantidade de encontros permitiu a construção de um vínculo com os educandos que não teria sido possível em atividades pontuais.

Anteriormente à primeira oficina, foi solicitado aos estudantes que respondessem a um formulário de participação no projeto. Neste documento havia perguntas acerca dos seus dados socioeconômicos, como também sobre suas concepções prévias com relação ao meio ambiente e à própria APAA. Já no encontro de finalização das oficinas, houve também a aplicação de um questionário focado na avaliação do projeto "Descobrindo Anhatomirim", no qual os estudantes elencaram as atividades melhor disfrutadas, fizeram sugestões para continuidade das atividades, e responderam a seguinte pergunta: "Existe alguma relação entre valorizar nossa cultura e proteger o meio ambiente? Por quê?", concluindo assim o ciclo de oficinas. 


\section{Análise de dados}

Foram escolhidos dois focos principais para análise dos resultados e a discussão ${ }^{5}$. O primeiro teve foco nas narrativas, percepções e saberes dos estudantes para com a APAA e sua sociobiodiversidade. Consistiu numa reflexão acerca do conhecimento etnoecológico que já existia dentro do espaço escolar, com ênfase em questões que se sobressaíram a partir das narrativas dos estudantes.

A análise das falas dos alunos, dos seus textos escritos e da entrevista realizada com a Dona Aléci, basearam-se principalmente nos estudos sobre narrativas. Reigota (1999) coloca como as narrativas caracterizam-se pelo uso da memória sobre eventos e suas significações, estando assim mais próximas da ficção. Isso não significa que ela seja deturpada, mas sim que os fatos são vivenciados de forma singular por cada indivíduo.

Já o segundo foco de análise se deu na relação educativa que foi construída junto aos estudantes, ao se discutir uma das atividades realizadas, avaliando o processo educativo alcançado durante o projeto. Também consistiu numa análise da prática do primeiro autor deste trabalho enquanto educador ambiental, sendo uma reflexão daquilo que foi feito e do porquê de tais escolhas.

\section{Resultados e discussão}

\section{A Etnoecologia na Vivência dos Estudantes}

Ao todo 19 alunos responderam ao formulário inicial de participação do projeto. Estes jovens que participaram das oficinas tinham entre 12 e 14 anos de idade, sendo que 10 dos alunos participantes das oficinas tinham famílias que viviam há mais de uma geração em Governador Celso Ramos. O restante vinha de núcleos familiares de imigração mais recente para o município, oriundos de locais como Anitápolis, Itapema, Florianópolis, São José e Tijucas.

De acordo com o questionário, 13 estudantes disseram ter familiares que trabalham ou já trabalharam como profissionais da pesca artesanal ou da agricultura. Dessa forma, esse contexto próximo aos modos de vida tradicionais estava bastante presente no dia-a-dia dos alunos. Além de pescadores e agricultores, as profissões dos seus familiares incluíam diaristas, donos e donas de casa, pintores, cabelereiros, professores, cozinheiros, empresários e pedreiros.

Como a Etnoecologia está presente na vivência dos estudantes, em especial nas suas narrativas? As definições dadas para "meio ambiente" no questionário de diagnóstico inicial, antes do início da realização das oficinas,

${ }^{5}$ A descrição e as análises de todas as atividades efetuadas nos encontros fazem parte do Trabalho de Conclusão de Curso do primeiro autor.

Revbea, São Paulo, V. 12, № 1: 139-154, 2017. 
tiveram a presença marcante de algumas perspectivas. A maior parte das definições teve foco em aspectos biológicos ou "naturalistas", tal como caracterizado por Reigota (1995), sendo que os alunos e as alunas do projeto caracterizaram "meio ambiente" como: "natureza, animais", "devemos proteger a flora e a fauna", "natureza e vida", "animais, uma planta, um animal, entre outras coisas" e "a diversidade de seres vivos (biodiversidade)". Estas compõem uma visão que associa meio ambiente estritamente ao não-humano.

Frases usualmente associados com a questão ambiental também foram colocadas nessa questão: "é fundamental um ambiente limpo sem poluição", "limpar e proteger nossas florestas de poluição e também o nossos planeta", e "o meio ambiente é muito importante pois precisamos dele para sobreviver". Tal como colocado por Krelling (2009) ao presenciar tal tipo de manifestação, essas frases são reflexo de uma educação ambiental muitas vezes normativa e direcionada, que infelizmente acaba por condicionar formas "corretas" de se manifestar, gerando assim a repetição de estereótipos e clichês. É papel do educador ambiental crítico poder desconstruir visões uniformizadas acerca de como se relacionar com o ambiente.

Outras respostas tiveram uma associação mais ampla, incorporando também o ambiente urbano, como "pra mim significa muitas coisas, tipo melhorar nossa cidade e deixá-la mais bonita" e "o meio onde vivemos"6. Alguns alunos demonstram também uma associação afetiva com o conceito de meio ambiente: "uma das coisas mais importantes do mundo, uma coisa perfeita, maravilhosa e que eu amo" e "significa vida, paz, uma parte de mim pois sem ele não poderia respirar". Maturana (1998) explica como o ser humano se compõe numa combinação entre o emocional e o racional, sendo que isso se reflete na forma com a qual educamos e percebemos o mundo.

Com relação às definições para a APAA, há um desconhecimento grande dos alunos, visto que 11 dos 19 alunos que responderam os questionários nunca haviam escutado sobre essa unidade de conservação. Também foi comum a associação da APAA somente com a llha de Anhatomirim, o que na realidade representa uma pequena porção da área total da unidade de conservação. De acordo com dois distintos alunos: "ela é uma ilha que antigamente era forte para os portugueses se defenderem dos inimigos" e "é uma ilha e tem golfinhos".

Alguns alunos demonstram reconhecer a APAA como um espaço protegido: "penso que é um lugar onde tudo é protegido, digo todos animais e plantas são protegidos", "um grande passo para proteção do meio ambiente onde vivemos, pois fica bem perto de nós e nos mostra como é importante" e "protege o ambiente aquático, os peixes". Entretanto, os alunos não demonstravam conhecer maiores detalhes sobre como a APAA funcionava e qual era a sua origem.

\footnotetext{
${ }^{6}$ As falas e escritas dos estudantes foram mantidas tal como fornecidas para preservar sua autenticidade.
} 
Guimarães (2008) coloca a centralidade da cultura nos modos de ler o ambiente. Demonstra também como o contexto histórico influencia enormemente as formas de se perceber o ambiente, desde o tempo das grandes navegações até os movimentos ecológicos modernos. Marcos Reigota (1995) apresenta a necessidade do desenvolvimento na educação ambiental de uma visão "globalizante" de meio ambiente, a qual abarca aspectos naturais, políticos, sociais, econômicos, filosóficos e culturais.

Como promover um processo de aproximação reflexiva e afetiva com esse espaço? Esta sondagem inicial possibilitou direcionar os caminhos que vieram posteriormente a ser percorridos no desenrolar das oficinas. Ao longo destas, foi demonstrado aos alunos que a APAA era de fato muito maior do que a llha de Anhatomirim, sendo que alguns alunos se surpreenderam ao saberem que moravam no interior de uma unidade de conservação e que esta fazia parte de sua vida cotidiana. Da mesma forma, foi discutida com os alunos a importância da ampliação de um conceito de meio ambiente, o qual possa incluir aspectos socioculturais (REIGOTA, 2009).

Ao longo dos encontros, pode-se perceber como algumas dessas percepções são construídas dentro de um contexto local. No decorrer da última oficina realizada na escola Maria Amália, alguns alunos contaram histórias de como a infância de seus pais foi marcada pela caça de diferentes animais, o que era muitas vezes uma forma de ajudar na subsistência da família, além de ser uma distração ou forma de jogo. Hoje em dia esse não é um comportamento considerado aceitável para os alunos, sendo que eles falaram que isso também se refletiu nos próprios hábitos dos animais para com as pessoas: "Antigamente parece que as capivaras tinham bastante medo, mas eu vi uma delas nesses dias e ela não correu". Os alunos falaram de animais que eram anteriormente muito caçados, como o aracuã, o tucano e o tatu. Atualmente este tipo de atividade é punida pelo poder público, mesmo que de maneira ineficaz, já que os alunos reconheceram que ainda há pessoas que caçam na região. Apesar da importância da caça para muitas comunidades tradicionais no Brasil, nas últimas décadas a mídia e o movimento ambientalista pressionaram o estabelecimento de leis mais rigorosas contra esse tipo de atividade (FERNANDES-FERREIRA; ALVES, 2014).

Os alunos também puderam estabelecer diferentes relações das plantas com o seu cotidiano. "Tem o guaco, a erva-doce, o tancha, o alecrim... E pra olho gordo, pimenta!" disse a aluna M. de 14 anos. Algumas falas colhidas na oficina sobre plantas medicinais ilustram essas relações: "minha avó deu pra minha mãe uma mudinha de funcho" e "minha mãe toma capim-limão com gengibre para dormir". Quando foi falado acerca da espinheira-santa houve um grande desconhecimento por parte dos estudantes, pois apenas uma das alunas já tinha escutado o nome desta planta, apesar de não saber exatamente seu uso. Uma aluna também disse: "meu pai já foi agricultor, cultivava mandioca e milho". A agricultura, apesar de haver diminuído nas últimas décadas, ainda tem uma presença marcante no contexto histórico daquela comunidade.

Revbea, São Paulo, V. 12, № 1: 139-154, 2017. 
Dessa forma, os alunos apontaram a importância das plantas que são cultivadas em casa, sendo que estas se encontram ameaçadas por transformações em áreas urbanas, onde proliferam condomínios sem quintais e, quando ainda existem estes espaços verdes, ou eles diminuem de tamanho ou são cimentados. Pesquisas como a de Lacerda (2008), realizada no sertão da Lagoa do Peri em Florianópolis, demonstram que quintais podem ser importantes zonas de conservação da agrobiodiversidade, como também de manutenção dos conhecimentos tradicionais associados a essas plantas.

"Se construir um prédio em cima da natureza, a gente perde a infância" disse o aluno L. de 14 anos. Essa frase emblemática sintetizou o contato íntimo que esses jovens têm com os ambientes da região. Esta afirmação foi falada no decorrer da $4^{a}$ oficina, quando foi perguntado aos estudantes se eles concordavam que preservar a natureza também envolve preservar parte da sua cultura. Nas suas falas os alunos demonstraram que os diferentes espaços considerados de domínio da natureza, sejam estes terrenos baldios, trilhas, praias ou parques, são também terrenos do cultural e do lúdico. Nesses ambientes, muitas vezes fora da supervisão dos adultos, apresenta-se o palco de aventuras, descobertas e brincadeiras que fazem parte da vivência da infância. A força desta frase também demonstra que as transformações que estão a ocorrer nesses locais têm um impacto direto nas suas vivências.

\section{Conexões entre a Etnoecologia e uma Educação Ambiental Dialógica}

Quais as potencialidades que a Educação Ambiental pode despertar a partir das narrativas presentes na comunidade? A atividade escolhida para ser discutida foi uma das três mais bem avaliadas pelos estudantes no questionário aplicado na oficina final do projeto. Ela consistiu numa roda de conversa com os estudantes e dona Aléci. Aléci Monteiro, senhora de 84 anos e mãe de 11 filhos, é nascida e criada na comunidade da Fazenda da Armação em Governador Celso Ramos. Sua casa foi reconhecida pelos alunos como uma das mais antigas da região. Através do contato facilitado devido à sua neta ser uma das alunas envolvidas com as oficinas, Aléci se prestou a ajudar na última oficina realizada com os estudantes. Ela também havia sido funcionária da Escola Maria Amália por muitos anos e possuía um forte vínculo com aquele espaço.

Há a necessidade de valorizar e incluir na escola as pessoas que fazem parte da comunidade na qual ela está imersa. Esses indivíduos, com relação a questão da educação ambiental, podem também dar importantes contribuições acerca das mudanças culturais e ambientais que estão a ocorrer ou já ocorreram. Através da entrevista que foi realizada com os estudantes junto a Dona Aléci foi possível resgatar esse caráter de inclusão da comunidade para com a escola.

Nesse encontro procuramos também fugir das formalidades características de uma entrevista, realizando assim um diálogo aberto e 
participativo, no qual tanto o mediador-educador quanto os alunos pudessem conversar com Aléci sobre as diferentes questões que foram trabalhadas no decorrer das oficinas (Figura 1).

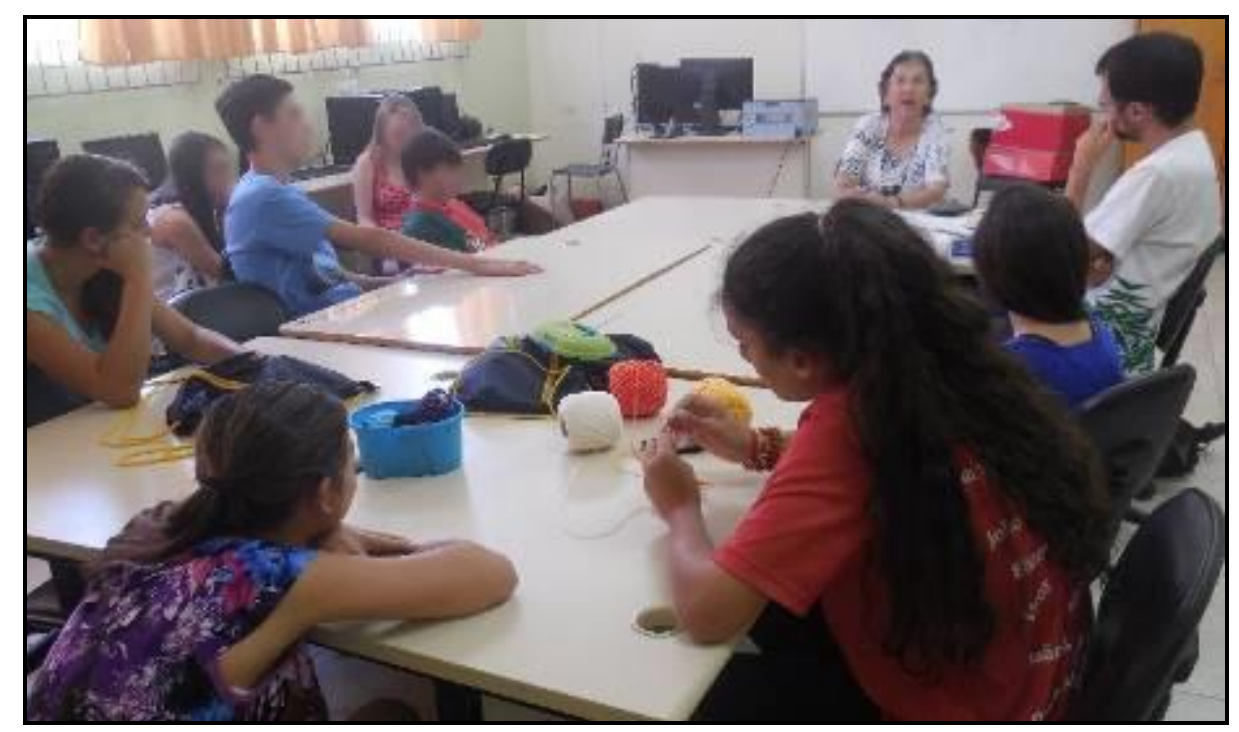

Figura 1: Foto da entrevista coletiva realizada com a Dona Aléci.

Fonte: Arquivo pessoal do primeiro autor

Nessa entrevista foi perguntado sobre temas que remetiam à vida e aos costumes de antigamente, produzindo assim um interessante diálogo entre o mediador-educador, os estudantes e Dona Aléci. São transcritos a seguir alguns trechos dessas narrativas dialogadas ${ }^{7}$, quando foi perguntado pelo educador sobre como a natureza da região havia se transformado nos últimos anos:

Mediador: Dona Aléci, você acha que mudou muita coisa na natureza aqui de Governador Celso Ramos?

Aléci: Ah, mudou, pelo menos esses rios, essas cachoeiras, tudo. Isso era uma maravilha. Agora a gente quase não tem água, esses rios estão tudo poluído. Aqui não era assim. No meu tempo não tinha isso, eles colocam esse esgoto pra esse rio, é até um perigo...

Aluno: O mangue também tá poluído né?

Aléci: É, mas olha, aquele mangue ali tá muito lindo. A gente chega ali na barra do rio e olha, ele tá bem fechado. Antes ele era seco, não sei se eles cortavam para tirar lenha também. Parece que eles cortavam para tirar lenha, porque antes todo mundo usava fogão de lenha, não tinha fogão à gás, eles iam no morro pegar lenha, todo mundo 
carregava a lenha do morro. E agora a gente olha essas matas, que coisa linda, tudo fechado.

Mediador: Então antes devastavam bastante a região, retiravam a madeira para fazer lenha.

Aléci: Palmito, antes eles cortavam muito palmito!

Aluno: Hoje tem gente que ainda corta.

Aléci: Tinha muita roça, eles plantavam muito, faziam aquelas queimadas, largavam o fogo, agora não se vê nada disso. Agora tá muito bom, eu acho.

Mediador: E tinha muito engenho aqui?

Aléci: Tinha também os engenhos de mandioca.

Mediador: Vocês sabem o que é um engenho? - Pergunto aos alunos.

Aluna: Aham, ali na Costeira tinha um!

Mediador: Sim, o pessoal plantava, colhia a mandioca e para processála levavam ao engenho para fazer a farinha.

Aléci: É, eles botavam no carro de boi as mandiocas. Aí tinha que raspar tudo aquela mandioca, direitinho. Botavam ela no balaio, levavam numa roda grande, pra moer tudo, o boi girava assim e aquela roda andava... Agora é tudo elétrico, é rápido. A gente botava num tapiti ${ }^{8}$ grande assim, que era feito. Aquilo eles apertavam para fazer a farinha. Ai, eu raspei muita mandioca lá na Costeira! Nós éramos pequenos assim - Aléci aponta para um aluno mais novo - A gente ajudava a raspar mandioca para ganhar beiju'!

Nesse trecho é possível observar como as mudanças culturais e econômicas, no caso do cultivo da mandioca, tiveram relação direta com transformações ambientais. Na visão da entrevistada, houve avanços na preservação das matas e manguezais, mas também um retrocesso na questão do uso dos recursos hídricos. Tal situação precária é confirmada no plano de manejo da APAA (ICMBIO, 2013b), segundo o qual apenas 7,77\% dos estabelecimentos no município de Governador Celso Ramos são conectados à rede geral de esgoto, sendo que fossas sépticas são utilizadas em 67,04\% dos casos e outros $14,42 \%$ dos estabelecimentos despejam diretamente seus efluentes em rios, lagos ou no mar.

As mudanças na vida dos pescadores e no ecossistema marinho também trouxeram interessantes reflexões:

\footnotetext{
8 Tapiti: cesto elástico fabricado com fibras vegetais, sendo um instrumento utilizado para espremer e secar a massa feita a partir da mandioca.

9 Beiju: alimento da culinária local feita a partir da massa da mandioca. Tem um preparo relativamente simples, sendo feito após torrar a massa numa chapa quente.
}

revista brasileira educação ambiental 
Mediador: Dona Aléci, e como era a vida dos pescadores?

Aléci: Ah, com os pescadores agora é bem fácil, antes era difícil, porque não tinha esses motor, não é? Era tudo a remo e a vela, eles iam pescar lá perto do Arvoredo, lá pra fora. Quando chegavam eram às 3 horas da tarde, saíam de madrugada e ainda não tinham voltado com um peixe. E tinha família que ainda estava esperando os pescador chegar para fazer o almoço. É... Porque antes a gente não tinha uma geladeira para guardar um peixe, principalmente no verão, né. Antigamente não tinha energia, não tinha nada.

Aluna: Antes enterravam as comidas, não é? Para ficar gelado. Mas aqui acho que não tinha muito por causa da areia da praia, aí não congelava bem.

Aléci: É, antes os peixes eram tudo escalado, agora não, botam no freezer.

Mediador: Como assim escalado?

Aléci: Era seco, botavam sal e botavam para secar, para conservar. Eu me lembro, o meu pai tinha lancha e eles pescavam bagre. Vocês conhecem o bagre?

Mediador: O bagre é o que tem espinho, né?

Aléci: É, ele tem aquele espinho que espeta, que é perigoso. Meu pai ia pescar, ele levava a rede na lancha, e ia umas duas, três pessoas para quando ele fosse pescar e pudessem carregar o peixe. Ele ia lá na Ponta Grossa ${ }^{10}$, em frente a ilha, bem no canal, eles pescavam aquelas manta ${ }^{11}$ de bagre, nós víamos quando estava pescado lá, e aí as outras lanchas atracavam, chegavam a ir na praia e descarregavam tudo na praia. E aí vinham as mulheres para limpar, era muito legal.

Aluno: O mar naquela época também era limpo, né. Hoje em dia não está mais.

Aléci: É, o mar era tudo limpo, o mar era uma beleza.

Mediador: Devia ter muito mais peixe também. Uma vez já ouvi uma história de um pescador em Tijucas que antigamente com um pano de rede dava de pegar quilos e quilos de peixe, enchia mesmo. Hoje em dia com o mesmo pano de rede, pega-se só um bagrezinho.

Aléci: É, hoje em dia não se pega nada. (...). Não tinha tanta lancha, tanta embarcação quanto tem agora. Eu tinha um tio que tinha uma canoa grande, ele puxava rede na praia. E aí ele começava a puxar a rede e ela vinha cheia desses camarão graúdo, meu deus! Três, quatro balaios de camarão, como tinha fartura! Aí tinha que cozinhar, aí meu pai comprava, cozinhava, tudo com sal assim, dava uma secadinha, e aí ele levava para vender lá no mercado.

${ }^{10}$ Referência à Fortaleza de São José da Ponta Grossa, localizada no norte da ilha de Santa Catarina.

${ }^{11}$ Manta: expressão local para cardume. 
Aluna: Se comparar assim, não era tão caro o camarão como é hoje em dia, né?

Aléci: É, mas agora a vida é mais fácil, a vida era mais difícil. (...) Antes o pessoal, quase todos era assim, eles trabalhavam durante o dia e à noite, eles iam à venda fazer compra, e assim pediam: meia caixa de fósforo, meia barra de sabão, meio quilo de açúcar, cem gramas de café, cem gramas de banha... Naquele tempo não tinha azeite, era banha. Tudo contadinho. Credo! Fazia daquele montão, um pacotinho de coisa, era difícil. Agora é aquela fartura, vamos no mercado e já está tudo pronto. Agora a vida está muito melhor.

Mais uma vez transformações econômicas, sociais e ambientais se mostram entrelaçadas. Dona Aléci relata 0 esgotamento dos estoques pesqueiros, no qual a pesca industrial ou de grande escala, quando agregada à pesca de pequena e média escala e aos impactos advindos da expansão urbana e industrial, tem contribuído para a sobreexplotação das populações de peixes no litoral brasileiro (CASTELLO, 2010). As inovações tecnológicas e a modernização econômica podem ser encaradas de maneira paradoxal, já que tanto podem ter levado a uma maior qualidade de vida às comunidades de Governador Celso Ramos, quanto a significativas perdas na qualidade ambiental e mudanças socioculturais.

Esta atividade remeteu aos chamados "círculos de cultura", tal como explicados por Paulo Freire (2011). O método Freireano consiste basicamente em primeiro fazer uma leitura do mundo, para após isso compartilhar essa leitura com os outros, sendo a educação um ato contínuo de produção e reconstrução de saber. Para isso estabelecem-se os "círculos de cultura", nos quais é fomentada a troca de ideias em coletividade. Compreende-se que ninguém educa ninguém de maneira unidirecional, assim como ninguém é capaz de educar-se a si próprio de forma absolutamente isolada; as pessoas educam-se entre si, tendo o mundo como intermediário. Essa roda de conversa que ocorreu entre o mediador, os alunos e Dona Aléci teve inspiração nesses pensamentos da Pedagogia Freireana.

São inúmeras as contribuições que os alunos e a comunidade podem trazer nas suas narrativas sobre o ambiente e nos seus saberes etnoecológicos para com atividades em educação ambiental. Diferentes temas transversais que estão presentes nos Parâmetros Curriculares Nacionais, tais como ética, meio ambiente e pluralidade cultural, são convergentes com os assuntos tratados pela Etnoecologia (HANAZAKI; FREITAS, 2011). Há uma necessidade crescente para que ocorra um diálogo entre 0 saber científico com 0 conhecimento tradicional, ambos presentes no contexto sociocultural dos alunos. É a partir desse pressuposto que será possível a realização de uma educação autenticamente dialógica, valorizando tanto a diversidade cultural e humana, quanto a diversidade biológica. Essa relação, entretanto, não está ausente de conflitos, já que práticas tradicionais também podem levar a 
impactos que degradam o ambiente. Essas e outras questões não devem ser evadidas, mas sim problematizadas e refletidas num processo educativo.

No questionário aplicado na finalização do projeto, especificamente na pergunta acerca da relação que os alunos conseguiam estabelecer entre a cultura e o meio ambiente, algumas respostas que se destacaram foram: "a cultura também faz parte do meio ambiente", "muitas culturas têm a ver com o meio ambiente, como por exemplo a pesca", "precisamos preservar a cultura, por que às vezes ela tem a ver com o meio ambiente" e "o ambiente traz um pouco de cultura e história". Os alunos demonstraram em diferentes momentos que foram capazes de tecer essas relações, tal como foi discutido continuamente durante as oficinas. Outros alunos, nas suas respostas, não encontraram essa conexão de imediato, mas reconheceram as atividades do projeto como proveitosas e fonte de distintos aprendizados.

\section{Conclusões}

O potencial que existe nos encontros entre a Etnoecologia e a Educação Ambiental é revelado especialmente na construção de narrativas pelos sujeitos. É através destas narrativas que continuamente são construídas e reconstruídas as diferentes formas de se compreender o mundo. No contexto específico vivenciado na APA do Anhatomirim, as narrativas dos alunos revelaram uma trajetória de transformação social e ambiental. Ao assumir um papel de mediação nesse processo educativo, foi aprendido junto aos alunos uma diversidade de saberes, desde os diferentes usos de plantas medicinais na comunidade até as lendas e causos contados de geração a geração, reafirmando-se assim o caráter dialógico dessa proposta de Educação Ambiental. Sobretudo, foi observada a beleza e a importância que existe nas relações tecidas entre o ser humano, sua cultura e a natureza.

Concluindo, esta experiência possibilitou vivenciar uma educação dialógica que trouxe aprendizados para ambos os lados, tanto ao educador como ao educando, sendo que estes papeis de fato alternaram-se frequentemente de posição. Esta investigação poderá inspirar futuros programas de educação ambiental na APA do Anhatomirim, como também em outros locais com contextos semelhantes. O Brasil possui uma riquíssima sociobiodiversidade, a qual constitui um patrimônio de valor insubstituível para o país, porém continuam as violações às populações tradicionais e indígenas, como também os danos à diversidade de ecossistemas e biomas. Por isso a importância de incorporar a valorização de conhecimentos ecológicos locais e dinâmicas específicas de sensibilização na forma de interagir com comunidades no contexto de unidades de conservação. 


\section{Agradecimentos}

Agradecemos a toda comunidade do bairro da Fazenda da Armação em Governador Celso Ramos, em especial à Dona Aléci e Seu Maneca, assim como aos alunos participantes das oficinas, à diretora Luciana, à coordenadora pedagógica Juliana e aos demais funcionários da Escola Básica Municipal Maria Amália Cardoso. Agradecemos ao Conselho Nacional de Desenvolvimento Científico e Tecnológico (CNPq) pela bolsa de produtividade em pesquisa (N. Hanazaki) que viabilizou financeiramente o estudo.

\section{Referências}

ALMEIDA, D.F.. Ensino de zoologia e conhecimentos prévios sobre animais: implicações conservacionistas. In: BAPTISTA, G.C.S.; VARGAS-CLAVIJO, M.; NETO, E.M.C. (Org.). A Etnobiologia na educação ibero-americana: compreensão holística e pluricultural da biologia. Feira de Santana: UEFS Editora, 2014. p. 217-236.

ALVES, A.G.C.; SOUTO, F.J.B. Etnoecologia ou Etnoecologias? Encarando a diversidade conceitual. In: ALVES, A.G.C.; SOUTO, F.J.B.; PERONI, N. (Org.). Etnoecologia em perspectiva: natureza, cultura e conservação. Recife: NUPPEA, v.3, 2010. p. 19-39.

ALVES, R. P.; HANAZAKI, N.. Coastal-marine protected areas in Santa Catarina under the local people's perspective: Contributions of the literature. Ambiente \& Sociedade, São Paulo v. 13, n. 4, p. 93-112, 2015.

ARRUDA, R. "Populações tradicionais" e a proteção dos recursos naturais em unidades de conservação. Ambiente \& Sociedade, Campinas v. 2, n. 5, p. 7991, 1999.

BRASIL. Lei 9.985 , de 18 de Julho de 2000. Publicada no Diário Oficial da União em 19 de Julho de 2000. Disponível em: $<$ http://www.planalto.gov.br/ccivil 03/leis/19985.htm> Acesso em 06/02/2017.

CASTELLO, J.P. O futuro da pesca e da aquicultura marinha no Brasil: a pesca costeira. Ciência e Cultura, Campinas, v. 62, n. 3, p. 32-35, 2010.

COUTINHO, L.M.; SARTOR, F.; ALARCON, G.; GUTSTEIN, C.S.; OLIVEIRA, C.H.S.; CARPEGGIANI, B.P.; WANDELLI, R.; SIMÕES, P.C. de A. Construindo a educação ambiental: uma experiência na Área de Proteção Ambiental (APA) de Anhatomirim. In: ARRUDA, V.L.V.; HANAZAKI, N. (Org.). Tecendo Reflexões em Educação e Meio Ambiente. 1 ed. Florianópolis: Editora da UFSC, 2011. p. 59-73.

FERNANDES-FERREIRA, H.; ALVES, R.R.N. Legislação e mídia envolvendo a caça de animais silvestres no Brasil: uma perspectiva histórica e socioambiental. Gaia Scientia [on-line], 2014, v. 8, n. 1, p. 1-7.

FREIRE, P. Pedagogia do oprimido. 50. ed. Rio de Janeiro: Paz e Terra, 2011. $256 \mathrm{p}$. 
GANDOLFO, E.S.; ULYSSÉA, M.A.; SILVA, S.D.M. da, LACERDA, V.D., HANAZAKI, N. A etnobiologia como zona de convergência entre ensino, pesquisa e extensão. In: GUIMARÃES, L.B.; KRELLING, A.G.; BARCELOS, V. (Org.). Educação Ambiental na arena cultural. 1 ed. Petrópolis: DP et Alii, 2010. p. 139-158.

GOMES, N.L.; SILVA, P.B.G. O desafio da diversidade. In: GOMES, N.L.; SILVA, P.B.G. (Org.). Experiências étnico-culturais para a formação de professores. Belo Horizonte: Autêntica Editora, 2002. p. 13-33.

GUIMARÃES, L.B. A importância da história e da cultura nas leituras da natureza. Inter-Ação: Revista da Faculdade de Educação UFG, Goiânia, v. 33, n. 1, p. 87-101, 2008.

HANAZAKI, N.; FREITAS, R.R. Etnoecologia, Educação e Meio Ambiente. In: ARRUDA, V.L.V. de; HANAZAKI, N. (Org.). Tecendo Reflexões em Educação e Meio Ambiente. 1 ed. Florianópolis: Editora da UFSC, 2011. p. 45-58.

ICMBIO. Plano de Manejo Encarte 1: Contextualização. 2013a. 64 p.

ICMBIO. Plano de Manejo Encarte 2: Diagnóstico da APA de Anhatomirim. 2013b. 156 p.

ICMBIO. Plano de Manejo Encarte 3: Zoneamento, Regramento e Planejamento da APA Anhatomirim. 2013c. 68 p.

KRELLING, A.G. Um Bosque com vida: encontros e experiências através da Educação Ambiental. 2009. 84 f. Trabalho de Conclusão de Curso (Licenciatura Plena em Ciências Biológicas). Universidade Federal de Santa Catarina, Florianópolis.

LACERDA, V.D. Quintais do Sertão do Ribeirão: Agrobiodiversidade sobre um enfoque etnobotânico. 2008. 61 f. Trabalho de Conclusão de Curso (Bacharelado Pleno em Ciências Biológicas). Universidade Federal de Santa Catarina, Florianópolis.

MATURANA, $H$. Emoções e linguagem na educação e na política. Belo Horizonte: UFMG, 1998. 98 p.

MARQUES, J.G.W. Pescando pescadores: uma etnoecologia abrangente no baixo São Francisco. São Paulo: NUPAUB-USP, 1995. 304 p.

NORBERG-HODGE, $H$. Ancient Futures: Lessons from Ladakh for a Globalizing World. São Francisco: Sierra Club Books, 2009. 226 p.

REIGOTA, M. O que é educação ambiental. São Paulo: Brasiliense, 2009. $112 \mathrm{p}$.

REIGOTA, M. Ecologistas. Santa Cruz do Sul: EDUNISC. 1999. 216 p.

REIGOTA, M. Meio ambiente e representação social. São Paulo: Cortez, 1995. 93 p.

VILÁ, B. La etnobiología y la educación ambiental en escuelas andinas del antiplano: reflexiones y experiencias. In: BAPTISTA, G.C.S.; VARGASCLAVIJO, M.; NETO, E.M.C. (Org.). A Etnobiologia na educação iberoamericana: compreensão holística e pluricultural da biologia. Feira de Santana: UEFS Editora, 2014. p. 315-353. 